\title{
RESEARCH
}

Open Access

\section{Evaluation of a mobile safety center's impact on pediatric home safety knowledge and device use}

\author{
Leah Furman $^{1 *}$, Stephen Strotmeyer ${ }^{2}$, Christine Vitale ${ }^{2}$ and Barbara A. Gaines ${ }^{2}$
}

From 24th Annual Injury Free Coalition for Kids Conference: Forging New Frontiers: Motor Vehicle Safety for All Ages Fort Lauderdale, FL, USA. 06-08 December 2019

\begin{abstract}
Background: A Mobile Safety Center (MSC) is designed to remove financial accessibility barriers to home safety by providing education and safety devices within local communities. The objective of this study was to evaluate the impact of an MSC on pediatric home safety knowledge and device use.

Methods: We conducted a prospective home safety interventional study. Parents and grandparents with children at home were recruited at community events attended by the MSC. Participants completed a pre-test survey assessing demographics and current home safety knowledge, practices, and device use. Participants then attended the MSC's short home safety educational program. Afterwards, participants completed a knowledge reassessment post-test and were offered free safety devices: a smoke detector, a gun lock, and a childproofing kit comprising outlet covers, doorknob covers, and cabinet latches. We administered two follow-up surveys four weeks and six months after visiting the MSC. Descriptive statistics, Friedman tests, Wilcoxon Sum-Rank tests, and Pearson ChiSquare were used to assess respondent demographic characteristics and changes in home safety knowledge, practices, and device use.
\end{abstract}

Results: We recruited 50 participants, of whom 29 (58\%) completed follow-up 1, 30 (60\%) completed follow-up 2, and 26 (52\%) completed both. Participants who completed both follow-ups increased total correct answers to safety knowledge questions between the pre-test and post-test $(p=0.005)$, pre-test and follow-up $1(p=0.003)$, and pre-test and follow-up $2(p=0.012)$ with no significant changes between the post-test, follow-up 1 , and follow-up 2. Of the respondents who reported accepting safety products, outlet covers were used most frequently, followed by the smoke detector, doorknob covers, cabinet latches, and the gun lock.

Conclusions: The MSC may be an effective means of increasing home safety among families with children, as participation in the MSC's home safety educational program significantly increased home safety knowledge and spurred home safety device use. Implementation of MSCs could potentially reduce childhood injury rates within communities through promotion of home safety.

Keywords: Gun lock, Home safety, Mobile safety center, Safety products, Smoke detector

* Correspondence: furman.leah@medstudent.pitt.edu
'University of Pittsburgh School of Medicine, Pittsburgh, PA, USA
Full list of author information is available at the end of the article

( ) The Author(s). 2020 Open Access This article is licensed under a Creative Commons Attribution 4.0 International License, which permits use, sharing, adaptation, distribution and reproduction in any medium or format, as long as you give appropriate credit to the original author(s) and the source, provide a link to the Creative Commons licence, and indicate if changes were made. The images or other third party material in this article are included in the article's Creative Commons licence, unless indicated otherwise in a credit line to the material. If material is not included in the article's Creative Commons licence and your intended use is not permitted by statutory regulation or exceeds the permitted use, you will need to obtain permission directly from the copyright holder. To view a copy of this licence, visit http://creativecommons.org/licenses/by/4.0/. The Creative Commons Public Domain Dedication waiver (http://creativecommons.org/publicdomain/zero/1.0/) applies to the data made available in this article, unless otherwise stated in a credit line to the data. 


\section{Background}

Unintentional injury is the leading cause of death for children older than 1 year and was responsible for nearly 6 million non-fatal pediatric injuries in the United States in 2017 (Web-based Injury Statistics Query and Reporting System (WISQARS), 2019). Home injuries, many of which are preventable, account for between 40 and 65\% of all unintentional child injuries (Morrison et al., 1999; Pitt et al., 1994; Hu et al., 1993). Barriers to child injury prevention include a general lack of safety information; poor timing of safety education, particularly at the time of a child's birth; inadequate or expensive safety devices; and parental inability to anticipate injuries (Smithson et al., 2011; Ablewhite et al., 2015; Ingram et al., 2012). Facilitators include provision of simple, durable safety devices; ability of parents to predict injury risk; community involvement; face-to-face education; and using methods tailored to each family's needs (Smithson et al., 2011; Ablewhite et al., 2015; Ingram et al., 2012; Kendrick et al., 2013). Many of these barriers and facilitators could be addressed by a safety center with a comprehensive injury prevention program. Indeed, the SAFE Home Project, or "SAFE trial," found personalized safety counseling and access to reduced-cost devices at a safety center were effective at improving home safety practices (Gielen et al., 2002).

In a follow-up study to the SAFE trial, barriers to visitation at a safety center were explored; for example, the studied center's limited schedule provided no hours outside of a typical workday (McDonald et al., 2003). This issue is particularly salient for families of lower socioeconomic status (SES), who may have inflexible job scheduling and limited access to transportation. The accessibility barrier is further compounded by the inverse relationship between SES and rates of unintentional pediatric injury (Bishai et al., 2002; Faelker et al., 2000; Pomerantz et al., 2001; Durkin et al., 1994; YumaGuerrero et al., 2018; Cubbin \& Smith, 2002; Fallat et al., 2006; Osborne et al., 2016; Gielen et al., 2012). To address the heightened risk of injury among low-SES families, some safety centers have created mobile safety centers (MSCs). MSCs potentially eliminate financial and transportation barriers and bolster community involvement by attending community events.

There are limited studies evaluating MSCs. These studies suggest MSCs are viewed positively by visitors and may increase safety knowledge and some behaviors (Gielen et al., 2009; Bulzacchelli et al., 2009). However, one study did not conduct follow-up and subsequently lacked long-term impact data (Gielen et al., 2009). Another study conducted follow-up but did not utilize the "mobile" aspect of the center. Instead, the MSC used during the latter study was periodically parked at a health center where participants had a preexisting relationship with healthcare providers (Bulzacchelli et al., 2009).

Regardless of mobile capability, the goal of any safety center should be injury rate reduction. The HOME injury study found installation of multiple safety items designed to reduce home injury hazards led to a $70 \%$ reduction in rate of modifiable medically attended injury. The study authors concluded there is significant value in the provision and use of safety products (Phelan et al., 2011). Yet recent data from a pediatric clinic suggest even freely-distributed safety items are not always used at home (Habermehl et al., 2019). Identifying "most used" items and focusing on the distribution of these higher-yield items in the future could increase the odds that families use the items they receive from a safety center or MSC.

In this study, we investigated whether an MSC could increase home safety knowledge and device use. We endeavored to mimic the settings that our MSC would attend in the future by recruiting participants through community events. Additionally, we examined which items were most frequently chosen to better tailor the items distributed at future events.

\section{Methods}

To evaluate the MSC, we conducted a prospective home safety interventional study approved by the University of Pittsburgh Institutional Review Board. The MSC attended six community events during a two-month period in 2018. The events were open to the public and held in low-income neighborhoods, except for one event, which was held for employees of a local company. One study team member distributed recruitment flyers to all event attendees. Parents or guardians (18 years or older) were eligible to participate in the study if they had children (less than 18 years old) living in their home. Some participants were grandparents caring for grandchildren.

After obtaining written informed consent, participants completed pre-tests comprising 12 questions assessing participant demographics, five questions assessing home safety knowledge (Fig. 1), and 17 questions assessing home safety behaviors. Most of these pre-test survey questions were modified from a similar survey previously used by the Safety Center at the University of Pittsburgh's Medical Center (UPMC) Children's Hospital of Pittsburgh as an assessment tool for conducting home safety evaluations prior to individualized education. This initial survey took approximately $10-15 \mathrm{~min}$ to complete and was scored at a Flesh-Kincaid reading grade level of 4.6 (Microsoft $^{\oplus}$ Word $^{\circ}$ Version 16.29.1). If a participant was unable to read, a study team member read each survey question and accompanying answer choices verbatim and entered each participant's answer accordingly. We also requested email addresses and phone numbers and 
Q1) The leading cause of death and disability for children is:

1. Cancer

2. Injury

3. Birth defects

\section{Q2) Children can drown in:}

1. An inch of water

2. A few seconds

3. Both answers

\section{Q3) If your child swallows something and you are unsure if it may be poisonous:}

1. Call the Poison Center Hotline or your physician immediately - this is a medical emergency

2. Observe your child - you only need to do something if vomiting occurs

3. Do nothing - household products aren't that dangerous, since you can buy them at the grocery store

Q4) If there is a fire, you should teach your child to:

1. Run upright through the smoke as fast as possible

2. Walk upright through the smoke slowly and carefully

3. Stay low below the smoke and crawl out

\section{Q5) The highest temperature in your water tank should be:}

1. 120 degrees $\mathrm{F}$ or less

2. 140 degrees $\mathrm{F}$ or less

3. 160 degrees $\mathrm{F}$ or less

Fig. 1 Five home safety knowledge questions participants answered during the pre-test, post-test, follow-up 1, and follow-up 2. Answer key: Question 1, Answer 2. Question 2, Answer 3. Question 3, Answer 1. Question 4, Answer 3. Question 5, Answer 1

asked that participants designate follow-up contact preferences (email, voice call, or text message).

Participants then attended the comprehensive safety program offered by the MSC. This program followed a standardized curriculum identical to the Safety Center at UPMC Children's Hospital of Pittsburgh and was taught by trained Safety Center staff members. Participants were taught in multiple small groups or one-on-one depending on event attendance, and education lasted approximately $20 \mathrm{~min}$ total. Topics included: safety in the kitchen, living/dining areas, and bathroom, and fire, firearm, and fall safety. All knowledge questions tested were covered during the program.

After completing the program, participants answered a five-question post-test identical to the five knowledge questions asked during the pre-test (Fig. 1). Afterwards, participants were given $\$ 5$ gift cards and offered free safety items: a smoke detector, a childproofing kit containing outlet covers, doorknob covers, and cabinet latches, and a gun lock. Participants could choose all three, a combination, or none. Pre-test and post-test surveys were conducted on provided tablet computers using Qualtrics $^{\circ}$ (Provo, Utah) or on paper copies of the printed Qualtrics ${ }^{\circ}$ survey, depending on participant preference.

We contacted participants to complete follow-up surveys 4 weeks after attending the program (follow-up 1 ). Follow-up 1 comprised five knowledge questions identical to the ones on the pre-test and post-test, 17 questions assessing home safety behaviors and risk factors identical to those on pre-test, and between one and 11 questions assessing use of items distributed, depending on how many items were taken. For text and email follow-up, we distributed links to a Qualtrics ${ }^{\circ}$ survey for participants to complete. When calling, the study team member read each question and all answer choices from an identical Qualtrics ${ }^{\circledR}$ survey verbatim over the phone to the participant and entered the selections. Contact 
occurred at fixed intervals for a total duration of 21 days (if call preferred) or 22 days (if text/email preferred). We spaced calling contact slightly differently than texting/ email to maximize variation in days of the week, as active text/email links could be answered at any convenient time. Regardless of modality, we contacted each participant at five unique timepoints, and began by only using the preferred modality. If a participant gave other modalities of contact, we simultaneously used these in conjunction with the preferred modality after two unsuccessful attempts. We accepted responses for 2 months after the first contact.

A week prior to follow-up 2, we notified participants that completion of this follow-up would automatically qualify them for a random chance to receive a $\$ 25$ gift card. Notifications were made via call or email. Then, 6 months post-MSC visit, we contacted participants to complete follow-up 2, with questions identical to followup 1. Contact occurred at fixed intervals as described above. Due to an initially non-working text link, we added an extra contact to all participants 1 week following the previous end point of contact. The winner of the gift card was notified 1 week after the study was closed for responses.

We examined demographics using range, median, and frequency percentiles. Participant answers to knowledge questions were scored as either 1 (correct) or 0 (incorrect) and totaled for all 5 knowledge questions. Unanswered knowledge questions were scored as a 0 . We calculated mean and standard deviation for total scores and used Friedman and Wilcoxon sum-rank (WSR) testing to identify significant differences between both total and individual pairs of scores. We analyzed item usage with Friedman and WSR testing and used Pearson ChiSquare analysis to assess mode effect. Concordance percentages were calculated by adding the number of participants who reported using an item during both follow-ups to the number who reported not using the item on both follow-ups and dividing by the total participants who reported receiving the item on both followups. For all statistics, a $p$-value less than 0.05 was considered significant. Results were analyzed using $\mathrm{IBM}^{\circ}$ SPSS $^{\circ}$ Statistics Version 25 (Mission Hills, CA).

\section{Results}

\section{Respondent demographics}

We enrolled 50 participants. The study population was primarily female (90\%) and was ethnically/racially similar to the population of Pittsburgh (Table 1). All participants had at least an 8th grade education; 80\% completed high school or equivalent, and $24 \%$ had a bachelor's degree or higher. Ages ranged from 23 to 71 years, with a median of 37 years. Most participants were married or in a domestic partnership (60\%) and
Table 1 Demographic breakdown of gender, race and education of study population compared to the population of Pittsburgh $^{\mathrm{a}}$

\begin{tabular}{|c|c|c|c|}
\hline \multicolumn{2}{|c|}{ Demographic Information } & \multirow{2}{*}{$\begin{array}{l}\text { Study } \\
\text { Population, } \\
\boldsymbol{N}=50 \\
\mathrm{n}(\%) \\
\\
45(90)\end{array}$} & \multirow{2}{*}{$\begin{array}{l}\text { Pittsburgh Population } \\
\text { Census Estimate } \\
\text { (\%)(United States } \\
\text { Census Bureau } \\
\text { QuickFacts Pittsburgh } \\
\text { city, Pennsylvania, 2018) } \\
\text { (51.1) }\end{array}$} \\
\hline Gender & Female & & \\
\hline & Male & $5(10)$ & $(48.9)$ \\
\hline \multirow[t]{6}{*}{ Race } & $\begin{array}{l}\text { Asian/Pacific } \\
\text { Islander }\end{array}$ & $5(10)$ & (5.6) \\
\hline & $\begin{array}{l}\text { Black or African } \\
\text { American }\end{array}$ & $10(20)$ & $(23.6)$ \\
\hline & Caucasian & $29(58)$ & $(64.7)$ \\
\hline & Hispanic or Latino & $3(6)$ & $(2.9)$ \\
\hline & Multiracial & $2(4)$ & (3.4) \\
\hline & $\begin{array}{l}\text { Native American } \\
\text { or American Indian }\end{array}$ & $1(2)$ & $(0.2)$ \\
\hline \multirow[t]{2}{*}{ Education } & $\begin{array}{l}\text { High School } \\
\text { Graduate, Diploma } \\
\text { or Equivalent or } \\
\text { Higher }\end{array}$ & $40(80)$ & $(92.1)$ \\
\hline & $\begin{array}{l}\text { Bachelor's Degree } \\
\text { or Higher }\end{array}$ & $12(24)$ & $(41.9)$ \\
\hline
\end{tabular}

a Pittsburgh population estimates based on data provided by the United States Census Bureau. Of note, educational statistics for the population of Pittsburgh are for adults age 25 years and older, as compared to 23 and older for our population

employed (56\%). Median annual income, \$25,000-\$34, 999, was lower than the $\$ 44,092$ median annual income in Pittsburgh (United States Census Bureau QuickFacts Pittsburgh city, Pennsylvania, 2018). Contact information was provided by 48 (96\%) participants, with 29 contactable participants completing follow-up 1 (60.4\%), 30 completing follow-up 2 (62.5\%), and 26 completing both (54.2\%) ("complete follow-up group").

\section{Knowledge}

When comparing changes in scores across tests for the complete follow-up group, scores on Questions 1 through 4 did not demonstrate significant differences, but there were significant differences for Question 5 $(p<0.001)$. Question 5 ("The highest temperature in your water tank should be:") was the most challenging for participants, as it was answered correctly by only $66 \%(33 / 50)$ of total participants on the pre-test, and $57.7 \%(15 / 26)$ of the complete follow-up group (Fig. 2). WSR testing for Question 5 revealed significant score improvement between the pre-test and the post-test $(p=0.001)$, follow-up $1(p=0.002)$, and follow-up 2 $(p=0.02)$, although the second follow-up score was significantly lower than the post-test score $(p=0.05)$. 


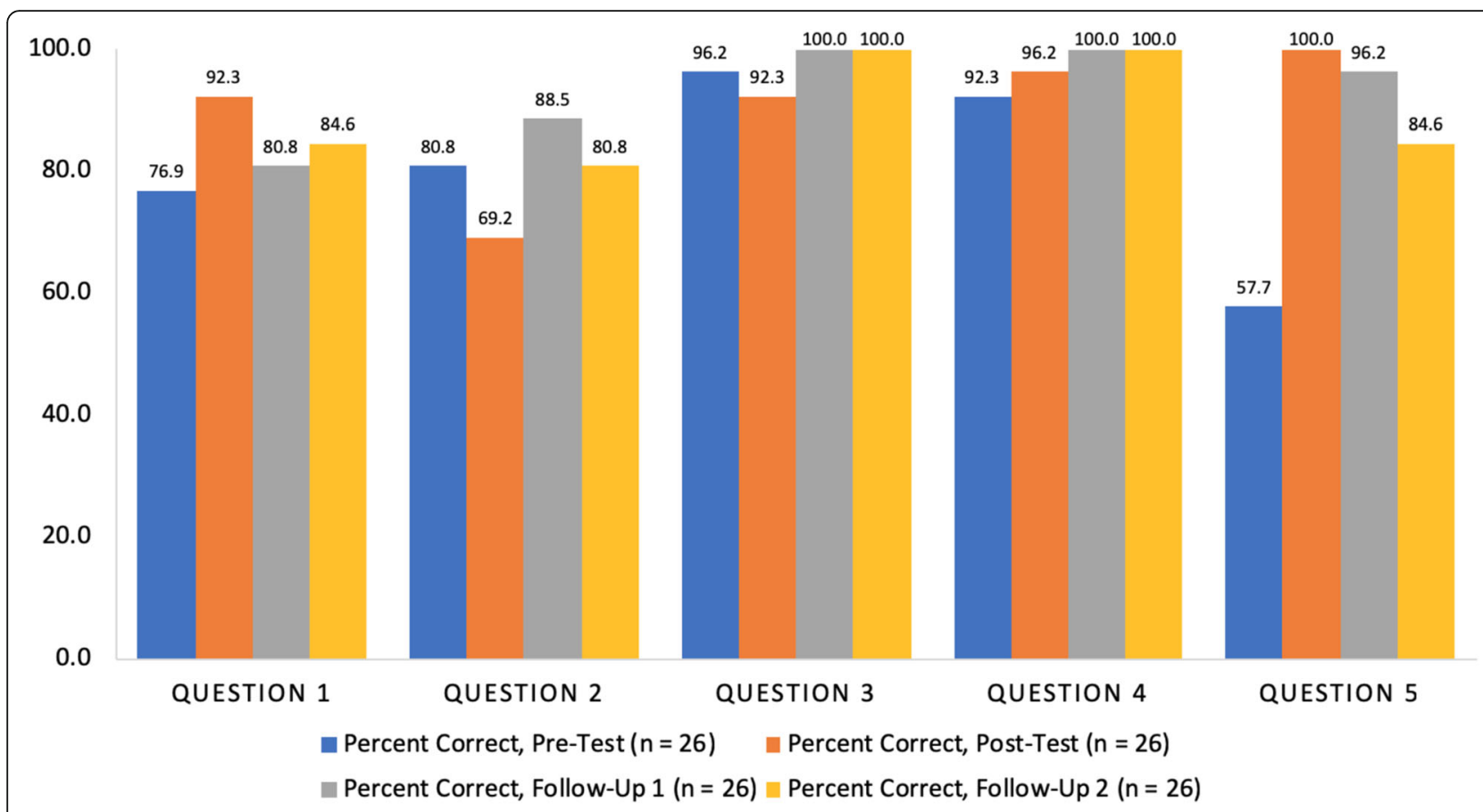

Fig. 2 Percentage of the complete follow-up group $(n=26)$ who answered each knowledge question correctly on the pre-test, post-test, followup 1 , and follow-up 2

Friedman testing of total scores from the complete follow-up group showed a significant difference between mean total scores, with mean scores of $3.9 \pm 0.6,4.5 \pm$ $0.4,4.6 \pm 0.4$, and $4.4 \pm 0.5$ for the pre-test, post-test, follow-up 1 and follow-up 2, respectively (Fig. 3). WSR testing of individual pairs of mean total scores for this group showed all other mean total scores were significantly increased from the pre-test mean total score (pretest vs. post-test, $p=0.005$; pre-test vs. follow-up $1, p=$ 0.003 ; pre-test vs. follow-up $2, p=0.01$ ). However, mean total scores after the pre-test were not significantly different from each other.

\section{Device use}

Of follow-up 1 respondents, 27/29 (93\%) accepted at least one item, while 29/30 (97\%) of follow-up 2 respondents did so. The childproofing kit was the most common choice. Outlet covers were most often reported to be in-use at both follow-ups (Table 2). Friedman testing showed usage of the three items in the childproofing kit was significantly different for both follow-ups $(p=0.002$ for follow-up 1 and $p=0.006$ for follow-up 2). WSR testing demonstrated outlet covers were used significantly more frequently than either doorknob covers or cabinet latches for follow-up 1. For follow-up 2, outlet covers were only used significantly more frequently than cabinet latches (Table 3).
We noted some discrepancies between follow-ups regarding item acceptance. For childproofing kits, 21 participants consistently reported receiving one, while three participants responded differently between follow-ups (concordance rate $=87.5 \%$ ). Gun locks had a similar concordance rate of $85 \%$, while smoke detector reports varied more, with a concordance rate of $56.5 \%$. Among participants who consistently reported receiving an item, reports of whether they were using the item also sometimes differed between follow-ups (Table 4). Electronic (text and email) vs. person-to-person (calling) mode effect was examined with Pearson Chi-Square analysis and only significantly impacted doorknob cover usage during follow-up 1 ( $p=0.04)$, with participants more likely to answer affirmatively when asked over the phone. None of the other items met statistical significance.

\section{Gun safety}

During the pre-test, 11 participants reported at least one firearm in their home. For storage at baseline, six participants used a gun safe, one used a gun lock, one used a locked cabinet or drawer, and three used a high place. At follow-up 1, four of the 11 participants who initially reported a firearm at home were lost to follow-up. The remaining seven included one individual who had previously reported owning a firearm then reported they did not own a firearm, and six who continued to report a firearm at home. For storage, five participants reported 


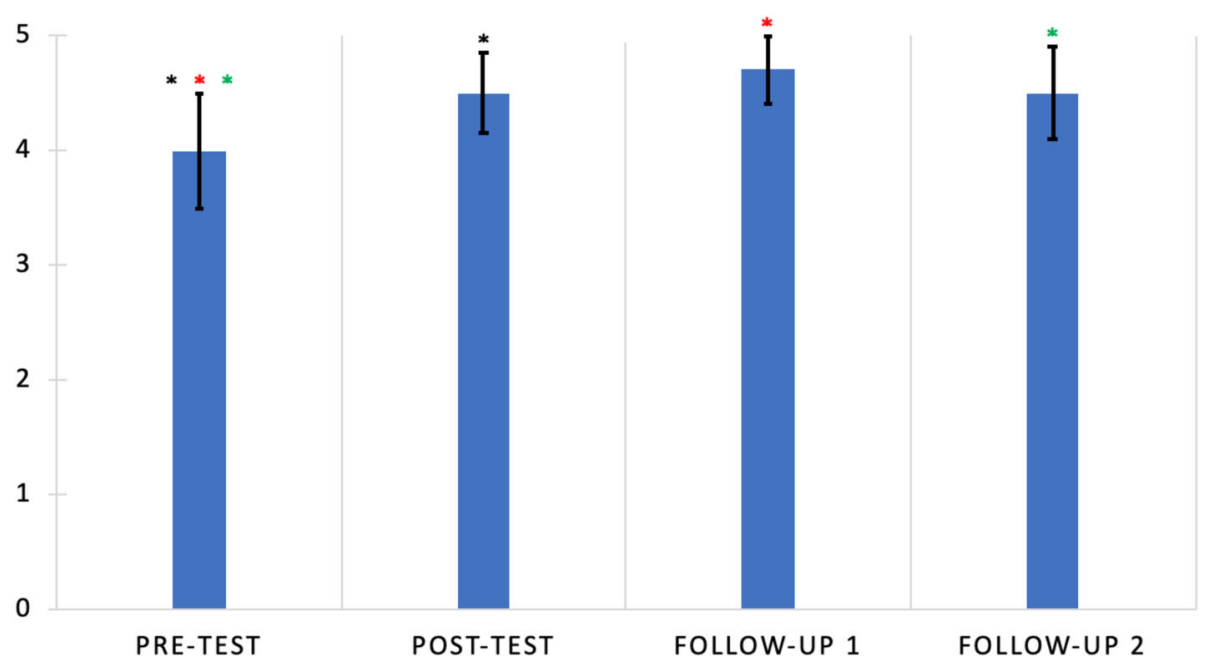

Fig. 3 Mean total scores for the complete follow-up group $(n=26)$ were significantly increased from pre-test to post-test, and these significant increases were maintained at both follow-ups. Wilcoxon sum-rank testing of each pairing individually revealed significant differences in scores between the pre-test and each other score (pre-test vs. post-test, $p=0.005$; pre-test vs. follow-up 1, $p=0.003$; pre-test vs. follow-up 2, $p=0.012$ ), but no other significant differences between pairs. Error bars represent standard deviation. Identically colored pairs of stars indicate significant differences between pairs

using a gun safe, and one continued to store it in a high place. At follow-up 2, the same six participants reported a firearm at home, and one person added a gun lock in addition to the gun safe. Interestingly, three participants consistently denied having a firearm at home, but reported taking and using a gun lock.

\section{Discussion}

Our study examined the use of an MSC as a tool for increasing home safety knowledge and device use, particularly among low-SES populations. Through community event attendance, we successfully recruited low-SES participants, increased home safety knowledge long-term, and distributed free safety products. We also found reported product usage varied considerably between items.

\section{Respondent demographics}

The MSC chose community events as recruitment sites to best reflect the future population that would be primarily served by the MSC. While most of these events served a low-income population, we included one event held at a local company to recruit a small number of middle- and higher-income participants. These events were chosen as our recruitment sites to best reflect the future population that would be served by the MSC: primarily low-income populations with some attendance from middle- and higher-income populations.

Overall, participants in our study had a lower median income, were less likely to have completed high school, and had fewer advanced degrees than the general population of Pittsburgh (United States Census Bureau QuickFacts Pittsburgh city, Pennsylvania, 2018), indicating that

Table 2 Device reception and use at first and second follow-up

\begin{tabular}{|c|c|c|c|c|c|c|c|}
\hline \multirow[t]{2}{*}{ Item } & & \multicolumn{3}{|c|}{ Follow-Up $1(n=29)$} & \multicolumn{3}{|c|}{ Follow-Up $2(n=30)$} \\
\hline & & $\begin{array}{l}\text { \# Received } \\
\text { Item }\end{array}$ & $\begin{array}{l}\text { \# Currently } \\
\text { Using }\end{array}$ & $\begin{array}{l}\text { \% Currently } \\
\text { Using }\end{array}$ & $\begin{array}{l}\text { \# Received } \\
\text { Item }\end{array}$ & $\begin{array}{l}\text { \# Currently } \\
\text { Using }\end{array}$ & $\begin{array}{l}\text { \% Currently } \\
\text { Using }\end{array}$ \\
\hline \multirow[t]{3}{*}{ Child-Proofing Kit } & $\begin{array}{l}\text { Doorknob } \\
\text { Covers }\end{array}$ & 26 & 15 & $57.7 \%$ & 25 & 18 & $72 \%$ \\
\hline & Outlet Covers & 26 & 22 & $84.6 \%$ & 25 & 22 & $88 \%$ \\
\hline & Cabinet Latches & 26 & 12 & $46.2 \%$ & 25 & 12 & $48 \%$ \\
\hline \multirow{2}{*}{$\begin{array}{l}\text { Non-Child-Proofing } \\
\text { Kit }\end{array}$} & Smoke Detector & 19 & 16 & $84.2 \%$ & 22 & 19 & $86.4 \%$ \\
\hline & Gun Lock & 19 & 4 & $21.1 \%$ & 20 & 5 & $25 \%$ \\
\hline
\end{tabular}

Items in the childproofing kit (outlet covers, doorknob covers, cabinet latches) are listed separately than those not in the kit (smoke detector, gun lock) to reflect the usage differential of the individual items 
Table 3 Differences in childproofing kit item usage during follow-up

\begin{tabular}{|c|c|c|c|c|c|c|}
\hline \multirow[b]{2}{*}{ Wilcoxon Sum-Rank Pairs } & \multicolumn{3}{|l|}{ Follow-Up 1} & \multicolumn{3}{|l|}{ Follow-Up 2} \\
\hline & $\begin{array}{l}\text { Outlet Covers } \\
+ \\
\text { Doorknob Covers }\end{array}$ & $\begin{array}{l}\text { Outlet Covers } \\
+ \\
\text { Cabinet } \\
\text { Latches }\end{array}$ & $\begin{array}{l}\text { Doorknob Covers } \\
+ \\
\text { Cabinet } \\
\text { Latches }\end{array}$ & $\begin{array}{l}\text { Outlet Covers } \\
+ \\
\text { Doorknob Covers }\end{array}$ & $\begin{array}{l}\text { Outlet Covers } \\
+ \\
\text { Cabinet } \\
\text { Latches }\end{array}$ & $\begin{array}{l}\text { Doorknob Covers } \\
+ \\
\text { Cabinet } \\
\text { Latches }\end{array}$ \\
\hline Significance & $p=0.008^{*}$ & $p=0.002^{*}$ & $p=0.32$ & $p=0.21$ & $p=0.002^{*}$ & $p=0.06$ \\
\hline
\end{tabular}

Friedman testing of childproofing kit item usage for both follow-ups revealed significant differences ( $p=0.002$ for follow-up 1, and $p=0.006$ for follow-up 2 ).

Significant $p$-values are indicated in italics with a star

the MSC was successful in reaching lower-SES communities. This is particularly crucial given the association between low SES and higher rates of pediatric injury (Bishai et al., 2002; Faelker et al., 2000; Pomerantz et al., 2001; Durkin et al., 1994; Yuma-Guerrero et al., 2018; Cubbin \& Smith, 2002; Fallat et al., 2006; Osborne et al., 2016; Gielen et al., 2012). We suggest our success in contacting lower-SES populations was largely due to our ability to bring the MSC to community events, thus leveraging the mobile capability of the MSC to primarily focus on the most at-risk population.

\section{Knowledge}

The five questions used to assess knowledge gains examined a range of content presented in conjunction with various aspects of home safety. Only Question 5, "The highest temperature in your water tank should be:" was answered significantly differently across time points, with pre-test scores significantly lower than any subsequent scores. Notably, Question 5 was the question answered incorrectly most often prior to the educational program, suggesting participants learned the answer during the program. However, the percentage of participants answering Question 5 correctly dropped significantly between the post-test and follow-up 2, perhaps indicating some knowledge loss. Despite this, both mean follow-up scores were still significantly higher than the mean pre-test baseline, suggesting that the MSC increases knowledge long-term.

Totaling knowledge scores magnified smaller changes seen for Questions 1 through 4. Altogether, participants increased their total score from the pre-test to the posttest and sustained this increase at both follow-ups. No significant decrease in knowledge occurred for total knowledge scores, reinforcing the indication that MSC education increased safety knowledge long-term. While our significance seemed to be primarily driven by Question 5, Question 5 was possibly the most representative of true "knowledge gains," because, as noted above, it was the question answered correctly least often on the pre-test. Our results echo Bulzacchelli et al.'s finding that visiting a stationary, health center-associated MSC was effective at increasing safety knowledge (Bulzacchelli et al., 2009). Furthermore, our gains were made in participants attending community events, a situation that is better reflective of the effectiveness of the MSC.

\section{Device use}

The discrepancies in reported item acceptance highlight a limitation of the study design: we allowed participants to choose which items to take without independently recording their choices. Our design likely reduced item redundancy and waste, as families who already owned an item could choose not to take another. Our methods may also have reduced the stigma some families felt by

Table 4 Item usage reports for respondents who reported receiving the item on both follow-ups

\begin{tabular}{|c|c|c|c|c|c|}
\hline & $\begin{array}{l}\text { Follow-up } 1 \text { Yes, Follow- } \\
\text { Up } 2 \text { Yes }\end{array}$ & $\begin{array}{l}\text { Follow-up } 1 \text { Yes, } \\
\text { Follow-Up } 2 \text { No }\end{array}$ & $\begin{array}{l}\text { Follow-up } 1 \text { No, Follow- } \\
\text { Up } 2 \text { Yes }\end{array}$ & $\begin{array}{l}\text { Follow-up } 1 \text { No, } \\
\text { Follow-Up } 2 \text { No }\end{array}$ & $\begin{array}{l}\text { Follow-Ups in Concordance, } \\
\text { Percentage }\end{array}$ \\
\hline $\begin{array}{l}\text { Doorknob } \\
\text { Covers } \\
(n=21)\end{array}$ & 9 & 2 & 5 & 5 & $66.7 \%$ \\
\hline $\begin{array}{l}\text { Outlet } \\
\text { Covers } \\
(n=21)\end{array}$ & 16 & 1 & 3 & 1 & $81.0 \%$ \\
\hline $\begin{array}{l}\text { Cabinet } \\
\text { Latches } \\
(\mathrm{n}=21)\end{array}$ & 5 & 5 & 5 & 6 & $52.4 \%$ \\
\hline $\begin{array}{l}\text { Smoke } \\
\text { Detector } \\
(n=13)\end{array}$ & 11 & 0 & 1 & 1 & $92.3 \%$ \\
\hline $\begin{array}{l}\text { Gun Lock } \\
(n=17)\end{array}$ & 3 & 1 & 1 & 12 & $88.2 \%$ \\
\hline
\end{tabular}


taking all items, particularly regarding gun locks. However, this impacted our ability to know with certainty which items each participant took.

We did not ask participants why they did or did not use an item. However, some possible reasons include: ease or difficulty of installation, perceived importance of safety product, and whether they understood the purpose of the item. We found of the three items in the childproofing kit, outlet covers were reportedly used significantly more frequently than cabinet latches at both follow-ups. This difference could reflect that these items are at the extremes of difficulty for installation, as the outlet covers can just be plugged in as-is while the cabinet latches required home hardware to install.

We found a significant mode effect when comparing usage reported electronically or over-the-phone only for doorknob cover usage on follow-up 1, with more participants affirming usage over the phone. This could be respondent bias secondary to a desire to please the study team by asserting use when interacting more directly. However, doorknob covers were also the first item that participants were asked about, suggesting participants who may have felt pressured to report usage did not feel the need to do so more than once.

\section{Gun safety}

We assured all participants of confidentiality during the consent process and provided standard gun safety education without asking about gun ownership. Despite this, we considered whether the stigma and political polarization around gun ownership would impact the truthfulness of our results. Interestingly, the data did contain notable discrepancies in reports about ownership and storage across survey timepoints that the authors felt warranted further discussion.

During the pretest, one participant reported a firearm at home, but then denied this during follow-ups. Intriguingly, several participants denied having a firearm in the home, but reported using the gun lock that we had given to them. As mentioned earlier, discrepancies existed between follow-up 1 and follow-up 2 regarding reports of whether a participant took an item and used it. It is possible participants picked an answer unintentionally, or circumstances changed between follow-ups. It is also possible participants felt uncomfortable admitting to owning a firearm, but still used the gun lock provided by the MSC. This brings us to a key conclusion: blanket provision of education and tools promoting gun safety, without assessing ownership status, could be effective at changing behaviors.

\section{Limitations}

Our study had some notable limitations. As noted above, we did not independently record which safety items that each participant took, so we do not know with certainty the safety items obtained by each study participant. As with most survey-based studies, our responses were subject to participant recall and social desirability bias. We also recruited participants at community events with the same population that we intend to reach with the MSC in the future. In doing so we conducted convenience sampling, which may have been impacted by selection bias. Also, our sample size was small, and we lost over $40 \%$ of participants to follow-up, suggesting our followup results may have been further impacted by selection bias. Additionally, as shown in the mode effects analysis, our results may have been influenced by responder bias, as we relied on self-report. Of note, studies designed to explore the validity of self-report for home safety practices have been generally good to mixed, with some reporting accuracy as high as $100 \%$ for certain practices and others demonstrating over-reporting $17-24 \%$ of the time. However, it is worth noting these studies relied on home observation checks to validate parental report, which in itself may introduce bias (Lee et al., 2012; Hatfield et al., 2006; Yorkston et al., 2005). Finally, while our study did show some significant increases in safety knowledge, further work would be needed to determine whether this difference is clinically meaningful.

\section{Conclusions}

We conclude the MSC may increase home safety among families by expanding safety knowledge and spurring the use of some freely distributed devices. Certain items, such as outlet covers and smoke detectors, were used by families significantly more frequently, and it may be prudent to prioritize the distribution of these items in the future. Importantly, stationing the MSC at community events is effective at reaching low-SES families, a population particularly vulnerable to unintentional child injuries. Employment of MSCs could potentially reduce community-wide childhood injury rates through comprehensive home safety interventions.

\section{Abbreviations \\ MSC: Mobile safety center; SES: Socioeconomic status; UPMC: University of Pittsburgh Medical Center; WSR: Wilcoxon sum-rank}

\section{Acknowledgements \\ The authors would like to thank the members of the Injury Prevention Program who conducted the MSC home safety educational program: Zachary Musico, Marissa Newhams, and Myriam Angrisano Hernandez. We would also like to thank our clinical research coordinator, Min Shi.}

\section{About this supplement}

This article has been published as part of Injury Epidemiology Volume 7 Supplement 1, 2020: Proceedings from the 24th Annual Injury Free Coalition for Kids ${ }^{\oplus}$ Conference: Forging New Frontiers: Motor Vehicle Safety for All Ages. The full contents of the supplement are available online at https://injepijournal. biomedcentral.com/articles/supplements/volume-7-supplement-1. 


\section{Authors' contributions}

LF obtained participant consent, administered the pre-test and post-test, contacted participants for follow-up, analyzed and interpreted participant data, and contributed to manuscript writing. SS obtained participant consent and administered the pre-test and post-test to some participants, served as advisor for data analysis and interpretation, and contributed to manuscript writing. CV designed the educational curriculum used by the MSC. BAG served as advisor for data analysis and interpretation and contributed to manuscript writing. All authors read and approved the final manuscript.

\section{Funding}

The mobile safety center is a project generously funded by the John Gismondi Family Foundation. Additional support for this project was provided by the University of Pittsburgh School of Medicine Dean's Summer Research Program. Publication charges were funded by the Injury Free Coalition for Kids ${ }^{\oplus}$

\section{Availability of data and materials}

The datasets used and/or analyzed during the current study are available from the corresponding author on reasonable request.

\section{Ethics approval and consent to participate}

This study was granted approval by the University of Pittsburgh Institutional Review Board under PRO18020555. Written informed consent was obtained from all participants prior to participation.

\section{Consent for publication}

Not applicable.

\section{Competing interests}

The authors declare that they have no competing financial or non-financial interests.

\section{Author details}

'University of Pittsburgh School of Medicine, Pittsburgh, PA, USA.

2Department of Pediatric General and Thoracic Surgery, UPMC Children's Hospital of Pittsburgh, Pittsburgh, PA, USA

Published: 12 June 2020

\section{References}

Ablewhite J, Peel I, McDaid L, Hawkins A, Goodenough T, Deave T, et al. Parental perceptions of barriers and facilitators to preventing child unintentional injuries within the home: a qualitative study. BMC Public Health. 2015;15(1):280.

Bishai D, McCauley J, Trifiletti LB, McDonald EM, Reeb B, Ashman R, et al. The burden of injury in preschool children in an urban Medicaid managed care organization. Ambul Pediatr. 2002;2(4):279-83.

Bulzacchelli MT, Gielen AC, Shields WC, McDonald EM, Frattaroli S. Parental safety-related knowledge and practices associated with visiting a mobile safety center in a low-income urban population. Fam Community Health 2009;32(2):147-58.

Cubbin C, Smith GS. Socioeconomic inequalities in injury: critical issues in design and analysis. Annu Rev Publ Health. 2002;23(1):349-75.

Durkin MS, Davidson LL, Kuhn L, O'Connor P, Barlow B. Low-income neighborhoods and the risk of severe pediatric injury: a small-area analysis in northern Manhattan. Am J Public Health. 1994;84(4):587-92.

Faelker T, Pickett W, Brison R. Socioeconomic differences in childhood injury: a population based epidemiologic study in Ontario, Canada. Inj Prev. 2000;6(3): 203-8.

Fallat ME, Costich J, Pollack S. The impact of disparities in pediatric trauma on injury-prevention initiatives. J Trauma Acute Care. 2006;60(2):452-4

Gielen A, McDonald EM, Wilson MH, et al. Effects of improved access to safety counseling, products, and home visits on parents' safety practices: results of a randomized trial. Arch Pediat Adol Med. 2002;156(1):33-40.

Gielen AC, McDonald E, Frattaroli S, McKenzie LB, Backes B, Glenshaw M, et al. If you build it, will they come? Using a mobile safety Centre to disseminate safety information and products to low-income urban families. Inj Prev. 2009; 15(2):95-9.

Gielen AC, Shields W, McDonald E, Frattaroli S, Bishai D, Ma X. Home safety and low-income urban housing quality. Pediatrics. 2012;130(6):1053-9.
Habermehl N, Diekroger E, Lazebnik R, Kim G. Injury prevention education in the waiting room of an underserved pediatric primary care clinic. Clin Pediatr. 2019;58(1):73-8.

Hatfield PM, Staresinic AG, Sorkness CA, Peterson NM, Schirmer J, Katcher ML. Validating self reported home safety practices in a culturally diverse noninner city population. Inj Prev. 2006;12(1):52-7.

Hu X, Wesson D, Kenney B. Home injuries to children. Can J Public Health. 1993; 84(3):155-8.

Ingram JC, Deave T, Towner E, Errington G, Kay B, Kendrick D. Identifying facilitators and barriers for home injury prevention interventions for preschool children: a systematic review of the quantitative literature. Health Educ Res. 2012;27(2):258-68.

Kendrick D, Young B, Mason-Jones AJ, Ilyas N, Achana FA, Cooper NJ, et al. Home safety education and provision of safety equipment for injury prevention (review). Evid Based Child Health. 2013:8(3):761-939.

Lee LK, Walia T, Forbes PW, Osganian SK, Samuels R, Cox JE, Mooney DP. Home safety practices in an urban low-income population: level of agreement between parental self-report and observed behaviors. Clin Pediatr (Phila) 2012;51(12):1119-24.

McDonald EM, Gielen AC, Trifiletti LB, Andrews JS, Serwint JR, Wilson MEH. Evaluation activities to strengthen an injury prevention resource center for urban families. Health Promot Pr. 2003:4(2):129-37.

Morrison A, Stone DH, Doraiswamy N, Ramsay L. Injury surveillance in an accident and emergency department: a year in the life of CHIRPP. Arch Dis Child. 1999;80(6):533-6.

Osborne JM, Davey TM, Spinks AB, McClure RJ, Sipe N, Cameron CM. Child injury: does home matter? Soc Sci Med. 2016;153:250-7

Phelan KJ, Khoury J, Xu Y, Liddy S, Hornung R, Lanphear BP. A randomized controlled trial of home injury hazard reduction: the HOME injury study. Arch Pediatr Adolesc Med. 2011;165(4):339-45.

Pitt WR, Balanda KP, Nixon J. Child injury in Brisbane south 1985-91: implications for future injury surveillance. J Paediatr Child H. 1994;30(2):114-22.

Pomerantz WJ, Dowd MD, Buncher CR. Relationship between socioeconomic factors and severe childhood injuries. J Urban Health. 2001;78(1):141-51.

Smithson J, Garside R, Pearson M. Barriers to, and facilitators of, the prevention of unintentional injury in children in the home: a systematic review and synthesis of qualitative research. Inj Prev. 2011;17(2):119-26.

United States Census Bureau QuickFacts Pittsburgh city, Pennsylvania. United States Census Bureau: Suitland, Maryland ; 2018 [cited 19 Jun 2019]. Available from: https://www.census.gov/quickfacts/pittsburghcitypennsylvania.

Web-based Injury Statistics Query and Reporting System (WISQARS). Centers for disease control and prevention: Atlanta, Georgia; 2019 [cited 19 Jun 2019]. Available from: https://www.cdc.gov/injury/wisqars/index.html.

Yorkston E, Turner C, Schluter P, McClure R. Validity and reliability of responses to a self-report home safety survey designed for use in a community-based child injury prevention programme. Int J Inj Control Saf Promot. 2005;12(3): 193-6.

Yuma-Guerrero P, Orsi R, Lee P-T, Cubbin C. A systematic review of socioeconomic status measurement in 13 years of U.S. injury research. J Saf Res. 2018:64:55-72.

\section{Publisher's Note}

Springer Nature remains neutral with regard to jurisdictional claims in published maps and institutional affiliations.

Ready to submit your research? Choose BMC and benefit from:

- fast, convenient online submission

- thorough peer review by experienced researchers in your field

- rapid publication on acceptance

- support for research data, including large and complex data types

- gold Open Access which fosters wider collaboration and increased citations

- maximum visibility for your research: over $100 \mathrm{M}$ website views per year

At BMC, research is always in progress.

Learn more biomedcentral.com/submissions 